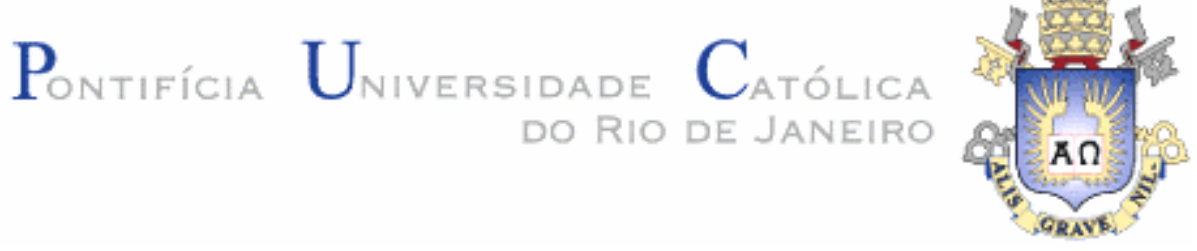

Samuel Felipe Mollepaza Tarazona

\title{
Modelagem centrífuga da movimentação lateral e axial de dutos em leito marinho arenoso
}

Dissertação de Mestrado

Dissertação apresentada como requisito parcial para obtenção do grau de Mestre pelo Programa de PósGraduação em Engenharia Civil do Departamento de Engenharia Civil da PUC-Rio.

Orientador: Prof. Celso Romanel

Co-Orientador: Prof. Márcio de Souza Soares de Almeida

Rio de Janeiro

Abril de 2015 
Dissertação apresentada como requisito parcial para obtenção do grau de Mestre pelo Programa de Pós-Graduação em Engenharia Civil do Departamento de Engenharia Civil do Centro Técnico Científico da PUC-Rio. Aprovada pela Comissão Examinadora abaixo assinada.

Prof. Celso Romanel Orientador

Departamento de Engenharia Civil - PUC-Rio

Prof. Marcio de Souza Soares de Almeida Co-Orientador Universidade Federal do Rio de Janeiro

Prof. Alberto de Sampaio Ferraz Jardim Sayão Departamento de Engenharia Civil - PUC-Rio

Prof. Fernando Saboya Albuquerque Junior Universidade Estadual do Norte Fluminense

Prof. José Renato Moreira da Silva de Oliveira Instituto Militar de Engenharia

Prof. José Eugenio Leal Coordenador Setorial do Centro

Técnico Científico - PUC-Rio 
Todos os direitos reservados. É proibida a reprodução total ou parcial do trabalho sem autorização da universidade, do autor e do orientador.

\section{Samuel Felipe Mollepaza Tarazona}

Graduou-se em Engenharia Civil pela Universidade Católica de Santa Maria, em 2011. Principais áreas de interesse: mecânica de solos, geotecnia offshore e melhoramento de solos.

Ficha Catalográfica

Tarazona, Samuel Felipe Mollepaza

Modelagem centrífuga da movimentação lateral e axial de dutos em leito marinho arenoso / Samuel Felipe Mollepaza Tarazona ; orientador: Celso Romanel ; co-orientador: Márcio de Souza Soares de Almeida. - 2015.

162 f. : il. (color.) ; $30 \mathrm{~cm}$

Dissertação (mestrado)-Pontifícia Universidade Católica do Rio de Janeiro, Departamento de Engenharia Civil, 2015.

Inclui bibliografia

1. Engenharia civil - Teses. 2. Modelagem centrífuga. 3. Interação solo-duto. 4. Resistência breakout. I. Romanel, Celso. II. Almeida, Márcio de Souza Soares de. III. Pontifícia Universidade Católica do Rio de Janeiro. Departamento de Engenharia Civil. IV. Título. 


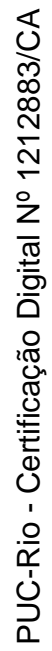

Aos meus pais Felipe e Alicia À minha amada esposa e adorada filhinha 


\section{Agradecimentos}

Agradeço primeiramente À Deus pela vida manifesta através do seu filho unigênito Jesus Cristo, Quem veio a este mundo para nos salvar.

Agradeço aos meus pais Felipe e Alicia pelo amor, incentivo e fortaleza que me deram.

A meu orientador Celso Romanel pelo apoio constante.

A meu orientador Marcio Almeida pelo apoio incondicional e pela oportunidade de desenvolver este trabalho.

Ao Departamento de Engenharia Civil da PUC-Rio.

À equipe da centrífuga, em especial a Pablo Trejo e Mario García por toda amizade, ajuda e colaboração que me deram para a conclusão deste trabalho.

À equipe do Laboratório de Geotecnia da COPPE.

À CAPES e FINEP pelo apoio financeiro.

À Technip pelo apoio nos trabalhos.

Finalmente agradeço a minha esposa pelo apoio incondicional e constante durante o desenvolvimento deste trabalho. 


\section{Resumo}

Tarazona, Samuel Felipe Mollepaza; Romanel, Celso; Almeida, Marcio de Souza Soares. Modelagem Centrífuga da Movimentação Lateral e Axial de Dutos em Leito Marinho Arenoso. Rio de Janeiro, 2015. 162 p. Dissertação de Mestrado - Departamento de Engenharia Civil, Pontifícia Universidade Católica do Rio de Janeiro.

Este trabalho aborda uma análise do problema de interação solo-duto através de modelagem em centrífuga da movimentação lateral e axial de dutos em modelos de areia submersa. Foi quantificada a resposta do solo ante a movimentação do duto em termos de mobilização das resistências pico (breakout), da evolução das forças resistentes durante a formação das bermas, e das trajetórias de forças verticallateral/axial combinadas que definem uma possível envoltória de fluência. Foi adotada uma simplificação básica dos cenários encontrados comumente na prática offshore. Para tanto, foram realizadas duas séries de ensaios em centrífuga geotécnica, aplicando deslocamentos laterais e axiais controlados em dutos com células de carga horizontal e vertical. Analisou-se históricos de carregamento plausíveis de acontecer no processo de lançamento do duto. Avaliou-se a influência do relaxamento das forças verticais decorrentes do enterramento do duto na mobilização das resistências lateral e axial. Resultados típicos dos ensaios são apresentados. Foi identificada a variação da resistência mobilizada, em termos de forças de breakout e forças máximas nas bermas, em função à relação entre as forças verticais de enterramento e as forças verticais no início da movimentação do duto. Os resultados revelam superfícies de fluência parabólicas em condições de carregamento vertical e lateral/axial combinado. Foi observado que as distâncias de mobilização das resistências axiais de breakout aumentaram em relação à porcentagem de enterramento do duto (w/D) divergindo de valores estimados na prática offshore que propõem distâncias constantes.

\section{Palavras-chave}

Modelagem centrífuga; interação solo-duto; resistência breakout. 


\section{Abstract}

Tarazona, Samuel Felipe Mollepaza; Romanel, Celso (Advisor); Almeida, Marcio de Souza Soares (Co-Advisor). Centrifuge Modelling of the Lateral and Axial Movements of Oil Pipes in a Sand Seabed. Rio de Janeiro, 2015. 162 p. MSc. Dissertation - Departamento de Engenharia Civil, Pontifícia Universidade Católica do Rio de Janeiro.

This study concerns the analysis of soil-pipeline interaction through centrifuge modelling of cyclic lateral and axial of pipeline movement in submerged sand models. Soil response related to pipeline movement was quantified in terms of breakout, evolution of resistance forces during berm formation, combined vertical-lateral/axial trajectories of forces that define a possible yield envelope. A simplification of common offshore scenarios was adopted. Two series of geotechnical centrifuge tests were accomplished by applying controlled lateral and axial movements to assess load history possible to occur in the process of pipeline laying. The influence of vertical stress relaxation due to pipeline embedment was assessed relative to vertical forces in the instance of the movements. Typical assay results are related. The variation of the mobilized resistance was identified in terms of breakout forces and maximum forces in the berms relative to vertical force history due to pipeline embedment. The results revealed parabolic yield surface in combined vertical-lateral/axial loading conditions. The mobilized distances of the breakout axial resistance increased in relation to pipeline embedment percentage (w/D) diverging from values estimated in offshore practice that propose constant distances.

\section{Keywords}

Centrifuge modelling; soil-pipeline interaction; breakout resistance. 


\section{Sumário}

1 Introdução 20

1.1. Motivação e objetivos 21

1.2. Estrutura da dissertação 21

2 Revisão Bibliográfica 23

2.1. Modelagem Física 23

2.2. Modelagem Física em Centrífuga 24

2.2.1. Leis de Escala para modelos quase-estáticos 25

2.3. Comportamento de solos arenosos 26

2.4. Interação Solo-Duto 30

2.4.1. Penetração Vertical 31

2.4.2. Resistência Axial solo-duto 35

2.4.3. Resistência Lateral 41

3 Materiais e Métodos $\quad 52$

3.1. Caracterização do material 52

3.1.1. Análise granulométrica 52

3.1.2. Análise Física $\quad 54$

3.1.3. Densidade real dos grãos $\quad 54$

3.2. Índice de Vazios $\quad 55$

3.2.1. Índice de vazios mínimo $\quad 55$

3.2.2. Índice de vazios máximo $\quad 57$

3.2.3. Índice de vazios por pluviação 59

3.3. Método de preparação da amostra 59

3.3.1. Procedimento do método de pluviação seca 60

3.4. Concepção dos Modelos Centrífugos 63

3.4.1. Duto de alumínio 63

3.5. Ensaios Preliminares $\quad 64$

3.5.1. Homogeneidade do solo do modelo 64

3.5.2. Enterramento do duto e alívio de tensões 65

3.5.3. Variação da velocidade de enterramento e arraste do duto 66 
3.6. Ensaios CPT 66

3.7. Concepção dos Ensaios $\quad 67$

3.8. Ensaio de arraste lateral 68

3.9. Ensaios de arraste axial 70

3.10. Equipamento e Instrumentação do Ensaio 73

3.10.1. Centrífuga de braço 73

3.10.2. Mini CPT 75

3.10.3. Célula de carga vertical 75

3.10.4. Célula de flexão horizontal 76

4 Resultados e análise da caracterização do solo e ensaios $\begin{array}{ll}\text { preliminares } & 77\end{array}$

4.1. Caracterização do solo $\quad 77$

4.1.1. Granulometria $\quad 77$

4.1.2. Índice de vazios mínimo 78

4.1.3. Índice de vazios máximo 78

4.1.4. Índice de vazios da amostra $\quad 79$

4.1.5. Análise dos resultados dos ensaios de laboratório 79

4.2. Ensaios preliminares 80

4.2.1. Homogeneidade do solo 80

4.2.2. Análise de resultados da homogeneidade do solo 81

4.2.3. Forças de atuação 81

4.2.4. Análise das forças de atuação 82

4.2.5. Enterramento do duto e alivio de tensões 84

4.2.6. Análise do enterramento do duto e alivio de tensões 86

4.2.7. Variação da velocidade de enterramento e arraste do duto $\quad 87$

4.2.8. Análise da variação de velocidade de enterramento e arraste do duto $\quad 89$

4.3. Ensaios CPT $\quad 89$

4.3.1. Análise dos ensaios CPT 90

5 Apresentação e análise de resultados dos ensaios de deslocamento $\begin{array}{ll}\text { lateral cíclico } & 92\end{array}$

5.1. Introdução 92 
5.2. Resultados dos ensaios de deslocamento lateral com $w / D=25 \%$

5.2.1. Análise de resultados dos ensaios de deslocamento lateral com

$w / D=25 \%$

5.3. Resultados dos ensaios de deslocamento lateral com $w / D=50 \% 104$

5.3.1. Análise de resultados dos ensaios de deslocamento lateral com $w / D=50 \%$

5.4. Resultados dos ensaios de deslocamento lateral com $\mathrm{w} / \mathrm{D}=75 \%$

5.4.1. Analise dos resultados dos ensaios de deslocamento laterais com $\mathrm{w} / \mathrm{D}=75 \%$

5.5. Análise geral dos resultados dos ensaios de deslocamento lateral com $w / D=25,50$ e $75 \%$

6 Apresentação e análise de resultados dos ensaios de deslocamento axial cíclico

6.1. Introdução

125

6.2. Resultados dos ensaios de deslocamento axial com $\mathrm{w} / \mathrm{D}=25 \%$

6.2.1. Analise de resultados dos ensaios de deslocamento axial com $w / D=25 \%$

6.3. Resultados dos ensaios de deslocamento axial com $w / D=50 \%$

6.3.1. Analise de resultados dos ensaios de deslocamento axial com $w / D=50 \%$

6.4. Resultados dos ensaios de deslocamento axial com $\mathrm{w} / \mathrm{D}=75 \%$

6.4.1. Analise de resultados dos ensaios axiais com $w / D=75 \%$

6.5. Análise geral dos resultados dos ensaios de deslocamento axial com w/D=25, 50 e $75 \%$

7 Conclusões e recomendações

7.1. Caracterização do solo e ensaios preliminares

7.2. Ensaios de deslocamento lateral cíclico

7.3. Ensaios de deslocamento axial cíclico 156

7.4. Sugestões 


\section{Lista de Figuras}

Figura 2.1 - Resultados de ensaios triaxiais CD na areia do Rio Sacramento.

(a) amostra compacta, $\mathrm{Dr}=100 \%$; (b) amostra fofa, $\mathrm{Dr}=25 \%$ (adaptado de Lee e Seed,1967).

Figura 2.2 - Desenho esquemático das contribuições à envoltória de Mohr das parcelas de atrito, dilatância e quebra dos grãos (adaptado de Lee e Seed,1967).

Figura 2.3 - Envoltória de Ruptura

Figura 2.4 - Tensão axial normalizada $v s$ deformação axial e deformação volumétrica $v s$ deformação axial.

Figura 2.5 - Resistência de atrito axial esquemática com deslocamento de mobilização e breakout (Bruton et al., 2008).

Figura 2.6 - Fator Horizontal de força para diversos ângulos de atrito (Trautmann e O'rourke, 1985).

Figura 2.7 - Modelagem hiperbólica e representação bilinear (Trautmann e O'rourke, 1985).

Figura 2.8 - Redução das forças verticais (direita) e acréscimo das forças horizontais (esquerda) durante a mobilização do duto em ensaios normalmente carregados (Zhang et al., 2001).

Figura 2.9 - Superfícies de fluência normalizadas (direita) e individuais (esquerda) em ensaios normalmente carregados (Zhang et al., 2001).

Figura 2.10 - Redução das forças verticais (direita) e acréscimo das forças horizontais (esquerda) durante a mobilização do duto em ensaios sobre carregados (Zhang et al., 2001).

Figura 2.11 - Superfícies de fluência normalizadas (direita) e individuais (esquerda) em ensaios sobre carregados (Zhang et al., 2001).

Figura 2.12 - Comparação da predição do modelo e resultados de ensaios

(Zhang et al., 2002).

Figura 2.13 - Trajetória de carregamento normalizada dos ensaios de arrastro (Zhang et al., 2002).

Figura 2.14 - Superfícies limite propostas (Zhang et al. 2002). 
Figura 2.15 Superfícies de potencial plástico propostas (Zhang et al., 2002). 50

Figura 3.1 - Colocação da areia no molde de ensaio. 56

Figura 3.2 - Sequência de colocação da sobrecarga na amostra e fixação do conjunto a ser ensaiado na mesa vibratória.

Figura 3.3 - Retirado de sobrecarga, nivelamento e pesagem da amostra do ensaio.

Figura 3.4 - Sequência da colocação da areia no molde de ensaio.

Figura 3.5 - Levantamento do tubo de parede rígida e nivelamento da areia do molde.

Figura 3.6 - Geotêxtil instalado na caixa (esquerda) e tela colocada no trilho da caixa (direita).

Figura 3.7 - Areia colocada no funil (esquerda) e funil posicionado para a pluviação (direita).

Figura 3.8 - Recipiente perfurado colocado no trilho da caixa (esquerda) e colocação da areia no recipiente para a pluviação (direita).

Figura 3.9 - Nivelamento da superfície da areia (esquerda) e superfície nivelada (direita).

Figura 3.10 - Submersão da areia.

Figura 3.11 - Distribuição em planta dos ensaios CPT.

Figura 3.12 - Vista de Elevação do ensaio lateral.

Figura 3.13 - Vista em planta do ensaio lateral. $\quad 70$

$\begin{array}{ll}\text { Figura } 3.14 \text { - Configuração geral do ensaio. } & 70\end{array}$

Figura 3.15 - Vista frontal do ensaio axial. 72

Figura 3.16 - Vista em planta do ensaio axial. 72

Figura 3.17 - Arranjo geral da centrífuga de braço (Broadbent Inc., 2011). 74

Figura 3.18 - Caixa de ensaio em deformação plana (Broadbent Inc., 2011). 74

$\begin{array}{ll}\text { Figura } 3.19 \text { - Arranjo do ensaio de mini-CPT. } & 75\end{array}$

Figura 3.20 - Configuração das células de carga e extensômetro utilizados. 76

Figura 4.1 - Distribuição granulométrica da amostra. 78

Figura 4.2 - Comparação dos perfis de resistência dos ensaios CPT nas amostras 1 e $2 . \quad 80$

Figura 4.3 - Forças vertical e horizontal do ensaio centrifugo. 81 
Figura 4.4 - Detalhe do acréscimo da força vertical e lateral devido à transmissão da aceleração centrífuga ao modelo, com amplificação do trecho D'E'F'.

Figura 4.5 - Variação da força vertical e lateral devido à atuação vertical do duto.

Figura 4.6 - Variação das Forças vertical e lateral devido à atuação lateral do duto.

Figura 4.7 - Forças vertical e lateral do ensaio centrifugo com relaxamento de força vertical.

Figura 4.8 - Forças vertical e lateral do ensaio centrifugo sem relaxamento de força vertical.

Figura 4.9 - Análise do processo de cravação nos ensaios com relaxamento das forças verticais.

Figura 4.10 - Força lateral vs Deslocamento lateral para enterramento de $25 \%$ do diâmetro, velocidade de enterramento e arraste do duto de $0,05 \mathrm{~mm} / \mathrm{s}$ do ensaio lateral 4.

Figura 4.11 Força lateral vs Deslocamento lateral para enterramento de $25 \%$ do diâmetro, velocidade de enterramento e arraste do duto de $0,5 \mathrm{~mm} / \mathrm{s}-$ Ensaio lateral 5.

Figura 4.12 Força lateral vs Deslocamento lateral para enterramento de $25 \%$ do diâmetro, velocidade de enterramento e arraste do duto de $5 \mathrm{~mm} / \mathrm{s}-$ Ensaio lateral 6.

Figura 4.13 - Perfis de resistência CPT dos ensaios de deslocamento lateral cíclico.

Figura 5.1 - Identificação de eventos típicos em um ensaio de deslocamento lateral cíclico do ensaio 1.

Figura 5.2 - Forca Lateral vs Deslocamento lateral para enterramento de $25 \%$ do diâmetro - Ensaio 7.

Figura 5.3 Forca vertical vs Deslocamento lateral para enterramento de 25\% do diâmetro - Ensaio 7.

Figura 5.4 Força lateral vs Deslocamento lateral para enterramento de $25 \%$ do diâmetro - Ensaio 8. 
Figura 5.5 Força vertical vs Deslocamento lateral para enterramento de $25 \%$ do diâmetro - Ensaio 8.

Figura 5.6 - Comparação entre as forças laterais e verticais do primeiro ciclo do ensaio de deslocamento lateral - Ensaio 1.

Figura 5.7 - Comparação entre as forças laterais e verticais do segundo ciclo do ensaio de deslocamento lateral - Ensaio 1.

Figura 5.8 - Variação das forças horizontais relativas à mobilização do breakout - Ensaios 7 e 8.

Figura 5.9 - Variação das forças verticais relativas à mobilização do breakout - Ensaios 7 e 8.

Figura 5.10 - Superfícies de fluência obtidas dos ensaios 7 e 8.

Figura 5.11 - Superfícies de fluência normalizada relativa à força vertical máxima dos ensaios 7 e 8.

Figura 5.12 - Variação das forças laterais máximas com os ciclos.

Figura 5.13 - Forças laterais máximas normalizadas vs o número de ciclos.

Figura 5.14 - Força lateral vs Deslocamento lateral para enterramento de $50 \%$ do diâmetro - Ensaio 9.

Figura 5.15 - Força vertical vs Deslocamento lateral para enterramento de $50 \%$ do diâmetro - Ensaio 9.

Figura 5.16 - Força lateral vs Deslocamento lateral para enterramento de $50 \%$ do diâmetro - Ensaio 10.

Figura 5.17 - Força vertical vs Deslocamento lateral para enterramento de $50 \%$ do diâmetro - Ensaio 10.

Figura 5.18 - Variação das forças laterais relativas à mobilização do breakout - Ensaios Laterais 9 e 10 (w/D=50\%).

Figura 5.19 - Variação das forças verticais relativas à mobilização do breakout - Ensaios Laterais 9 e 10 (w/D=50\%).

Figura 5.20 - Superfícies de fluência obtidas dos ensaios Laterais 9 e 10 $(\mathrm{w} / \mathrm{D}=50 \%)$.

Figura 5.21 - Superfícies de fluência normalizadas relativas às forças verticais máximas dos ensaios Laterais 9 e $10(\mathrm{w} / \mathrm{D}=50 \%)$.

Figura 5.22 - Variação das forças laterais máximas com os ciclos dos ensaios Laterais 9 e $10(\mathrm{w} / \mathrm{D}=50 \%)$. 
Figura 5.23 - Forças laterais máximas normalizadas $v s$ número de ciclos dos ensaios Laterais 9 e 10 (w/D=50\%).

Figura 5.24 - Força lateral vs Deslocamento lateral para enterramento de $75 \%$ do diâmetro - Ensaio 11.

Figura 5.25 - Força vertical vs Deslocamento lateral para enterramento de $75 \%$ do diâmetro - Ensaio 11.

Figura 5.26 - Força lateral vs Deslocamento lateral para enterramento de $75 \%$ do diâmetro - Ensaio 12.

Figura 5.27 - Força vertical vs Deslocamento lateral para enterramento de $75 \%$ do diâmetro - Ensaio 12.

Figura 5.28 - Variação das forças laterais relativas à mobilização do breakout dos ensaios laterais 11 e $12(\mathrm{w} / \mathrm{D}=75 \%)$.

Figura 5.29 - Variação das forças verticais relativas à mobilização do breakout dos ensaios laterais 11 e $12(\mathrm{w} / \mathrm{D}=75 \%)$.

Figura 5.30 - Superfície de fluência obtidas dos ensaios laterais 11 e 12 $(\mathrm{w} / \mathrm{D}=75 \%)$.

Figura 5.31 - Superfícies de fluência normalizada relativas à força vertical máxima dos ensaios laterais 11 e 12 (w/D=75\%).

Figura 5.32 - Variação das forças laterais máximas com os ciclos dos ensaios laterais 11 e $12(\mathrm{w} / \mathrm{D}=75 \%)$.

Figura 5.33 - Forças laterais máximas normalizadas vs número de ciclos dos ensaios laterais 11 e $12(\mathrm{w} / \mathrm{D}=75 \%)$.

Figura 5.34 - Comparação das forças laterais relativas à mobilização do breakout dos ensaios 8, 9 e $11(\mathrm{w} / \mathrm{D}=25,50$ e $75 \%$ respectivamente).

Figura 5.35 - Comparação das forças verticais relativas à mobilização do breakout dos ensaios 8,9 e $11(\mathrm{w} / \mathrm{D}=25,50$ e $75 \%$ respectivamente).

Figura 5.36 - Comparação das Superfícies de fluência obtidas dos ensaios 8,9 e 11 (w/D $=25,50$ e $75 \%$ respectivamente).

Figura 5.37 - Comparação das Superfícies de fluência normalizadas dos ensaios 8,9 e 11 (w/D $=25,50$ e $75 \%$ respectivamente).

Figura 5.38 - Comparação das curvas de fluência com as de Zhang et al. (2001). 
Figura 5.39 - Comparação de forças normalizadas obtidas experimentalmente e modelos propostos na literatura (modificado de Almeida et al., 2007). 123

Figura 6.1 - Identificação de eventos típicos durante o ensaio de deslocamento axial cíclico.

Figura 6.2 - Resultado final do ensaio de interação axial.

Figura 6.3 - Força axial vs Deslocamento axial para enterramento de 25\% do diâmetro - Ensaio 7.

Figura 6.4 - Força vertical vs Deslocamento axial para enterramento de $25 \%$ do diâmetro - Ensaio 7.

Figura 6.5 - Força axial vs Deslocamento axial para enterramento de 25\% do diâmetro - Ensaio 8.

Figura 6.6 - Força vertical vs Deslocamento axial para enterramento de $25 \%$ do diâmetro - Ensaio 8.

Figura 6.7 - Variação das forças axiais relativas à mobilização do breakout dos ensaios 07 e 08.

Figura 6.8 - Variação das forças verticais relativas à mobilização do breakout dos ensaios 7 e 8 .

Figura 6.9 - Superfície de fluência obtidas dos ensaios 7 e 8.

Figura 6.10 - Superfícies de fluência normalizadas relativas à força vertical máxima dos ensaios 7 e 8.

Figura 6.11 - Degradação das resistências axiais com o desenvolvimento dos ciclos para deslocamentos de 1,5D dos ensaios 7 e 8 .

Figura 6.12 - Resistências axiais normalizadas com o desenvolvimento dos ciclos para deslocamentos de 1,5D dos ensaios 7 e 8 .

Figura 6.13 - Força axial vs Deslocamento axial para enterramento de 50\% do diâmetro - Ensaio 9.

Figura 6.14 - Força vertical vs Deslocamento axial para enterramento de 50\% do diâmetro - Ensaio 9.

Figura 6.15 - Força axial vs Deslocamento axial para enterramento de 50\% do diâmetro - Ensaio 10.

Figura 6.16 - Força vertical vs Deslocamento axial para enterramento de 50\% do diâmetro - Ensaio 10. 
Figura 6.17 - Variação das forças axiais relativas à mobilização do

breakout dos ensaios 9 e 10.

Figura 6.18 - Variação das forças verticais relativas à mobilização do breakout dos ensaios 9 e 10.

Figura 6.19 - Superfícies de fluência obtidas dos ensaios 9 e 10.

Figura 6.20 - Superfícies de fluência normalizadas relativas à força vertical máxima dos ensaios 9 e 10.

Figura 6.21 - Degradação das resistências axiais com o desenvolvimento dos ciclos para deslocamentos de 1,5D dos ensaios 9 e 10 .

Figura 6.22 - Resistências axiais normalizadas com o desenvolvimento dos ciclos para deslocamentos de 1,5D dos ensaios 9 e 10 .

Figura 6.23 - Força axial vs Deslocamento axial para enterramento de $75 \%$ do diâmetro - Ensaio 11.

Figura 6.24 - Força vertical vs Deslocamento axial para enterramento de $75 \%$ do diâmetro - Ensaio 11.

Figura 6.25 - Força axial vs Deslocamento axial para enterramento de 75\% do diâmetro - Ensaio 12.

Figura 6.26 - Força vertical vs Deslocamento axial para enterramento de $75 \%$ do diâmetro - Ensaio 12.

Figura 6.27 - Variação das forças axiais relativas à mobilização do breakout dos ensaios 11 e 12 .

Figura 6.28 - Variação das forças verticais relativas à mobilização do breakout dos ensaios 11 e 12.

Figura 6.29 - Superfícies de fluência obtidas dos ensaios 9 e 10.

Figura 6.30 - Superfícies de fluência normalizada relativas à força vertical máxima dos ensaios 11 e 12.

Figura 6.31 - Degradação das resistências axiais com o desenvolvimento dos ciclos para deslocamentos de 1,5D dos ensaios 11 e 12 .

Figura 6.32 - Resistências axiais normalizadas com o desenvolvimento dos ciclos para deslocamentos de 1,5D dos ensaios 11 e 12 .

Figura 6.33 - Comparação das forças axiais relativas à mobilização do breakout dos ensaios 7, 9 e 12 . 
Figura 6.34 - Comparação das forças verticais relativas à mobilização do breakout dos ensaios 7, 9 e 12.

Figura 6.35 - Comparação das Superfícies de fluência dos ensaios 7, 9 e 12.151

Figura 6.36 - Comparação das Superfícies de fluência normalizadas dos ensaios 7, 9 e 12.

Figura 6.37 - Comparação das forças axiais relativas à mobilização do breakout dos ensaios 8, 9 e 11.

Figura 6.38 - Comparação das forças verticais relativas à mobilização do breakout dos ensaios 8, 9 e 11 .

Figura 6.39 - Comparação das Superfícies de fluência dos ensaios 8, 9 e 11.153

Figura 6.40 - Comparação das Superfícies de fluência normalizadas dos ensaios 8, 9 e 11 . 


\section{Lista de Tabelas}

Tabela 2.1 Relação entre escala e protótipo (Ko, 1988)

Tabela 2.2 - Parâmetros de Ruptura e Módulo de Elasticidade obtidos do ensaio triaxial CD

Tabela 2.3 Valores do fator de resistência para o coeficiente de atrito axial

Tabela 2.4 Valores do fator de rigidez do solo $C_{k}$

(Trautmann e O'rourke, 1985)

Tabela 3.1 Características da amostra 54

Tabela 3.2 Dimensões dos protótipos ensaiados. 64

Tabela 3.3 Características dos ensaios de arraste lateral

Tabela 3.4 Características dos ensaios de arraste axial realizados.

Tabela 4.1 Resultados dos ensaios de massa específica aparente seca máxima 78

Tabela 4.2 Resultados dos ensaios de massa específica aparente seca mínima

Tabela 4.3 Resultados dos ensaios de pluviação para determinação do índice de vazios da amostra

Tabela 4.4 Valores do ângulo de atrito, calculados a partir dos perfis CPT 90

Tabela 5.1 Resultados dos ensaios de deslocamento lateral cíclico.

Tabela 5.2 Parâmetros utilizados na estimativa dos valores de resistência lateral normalizada.

Tabela 6.1 Resultados dos ensaios de deslocamento axial cíclico. 